\section{El presente del pasado. Historia, memoria, literatura*}

The Past's Present. History, Memory, Literature

\section{Roger Chartier}

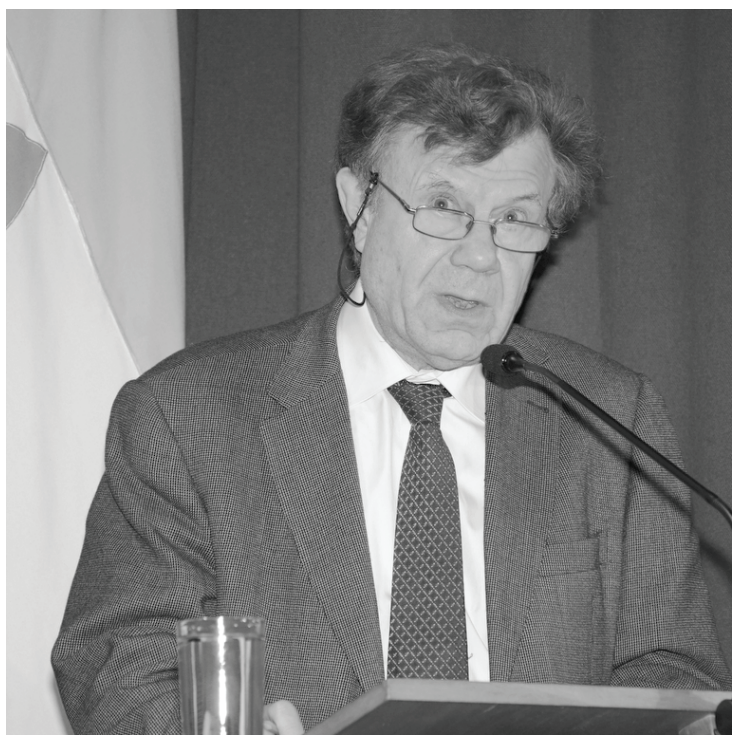

Conferencia dictada el 17 de octubre del 2016 en la Facultad de Filosofía y Humanidades de la Universidad Austral de Chile.
Es un gran honor y un gran placer para mí participar en el acto que celebra los 60 años de existencia de la Facultad de Filosofía y Humanidades de la Universidad Austral de Chile. Es la primera vez que estoy en Valdivia, pero no la primera en Chile. Para los franceses de mi generación, Chile no es un país como los otros. Después del mayo de 1968, Chile fue para nosotros una tierra de experiencia y de esperanza. Después del primer y siniestro 11 de septiembre, Chile hizo de nuestros "ojos una fuente de lágrimas llorando por los muertos", como fueron las lágrimas bíblicas del profeta Jeremías. Pero aquellos tiempos de dolor también fueron tiempos que fortalecieron la solidaridad entre todos los que, tanto en Chile como en Francia, compartían y comparten la inalterable esperanza en un mundo más justo, sin crueldades ni tiranías, para citar esta vez a Bartolomé de Las Casas. ¿Qué papel pueden desempeñar la historia (que es mi disciplina), y más generalmente las humanidades y las ciencias sociales, en la construcción del mundo que deseamos y que esperamos? Esta pregunta es el tema de mi conferencia.

Los historiadores siempre han sido lamentables profetas, pero, a veces, al recordar que el presente está hecho de pasados heredados y sedimentados, han podido contribuir a un diagnóstico más lúcido en cuanto a las novedades que seducían o espantaban a sus contemporáneos. Es esta certeza la que inspiraba a Lucien Febvre cuando, en una Europa todavía herida por la Primera Guerra Mundial, pronunció en 1933 la lección inaugural de la cátedra "Historia de la civilización moderna" en el Collège de France. Su vibrante defensa de una historia capaz de construir problemas e hipótesis, y no solamente de narrar acontecimientos, no estaba 
separada de la idea según la cual la historia, como toda ciencia, "no se hace dentro de una torre de marfil. Se hace en la vida misma, y por seres vivos que están inmersos en el siglo". Diecisiete años más tarde, en 1950, Fernand Braudel, quien le sucedió en esa cátedra, insistía aún más en las responsabilidades de la historia y de los historiadores, en un mundo conmocionado por segunda vez y privado de las certezas difícilmente reconstruidas en los años treinta. Para Braudel, al distinguir las temporalidades articuladas que caracterizan cada sociedad, era posible oír el permanente diálogo instaurado entre la larga duración y el acontecimiento, y así identificar las "profundas rupturas más allá de las cuales la vida de los hombres cambia por completo".

Estas proposiciones de los fundadores de la escuela de los Annales pueden guiar todavía nuestras reflexiones. Pero debemos también medir la distancia que nos separa de ellos. Nuestra obligación ya no consiste en reconstruir la disciplina histórica, tal como lo exigía un mundo dos veces en ruinas, sino en comprender mejor y aceptar que los historiadores no tienen en nuestras sociedades el monopolio de las representaciones del pasado. Las insurrecciones de la memoria y las seducciones de la ficción son fuertes competidoras. Hoy en día, los historiadores saben que el conocimiento que producen no es más que una de las modalidades de la relación que las sociedades mantienen con el pasado. Las obras de ficción, al menos algunas de ellas, y la memoria, sea colectiva o individual, también dan una presencia al pasado; a veces, o a menudo, una presencia más poderosa que la que establecen los libros de historia.

En los últimos años, la obra del filósofo francés Paul Ricœur, quien falleció en el 2005, es sin duda alguna la que dedicó más atención a los diferentes modos de representación del pasado: la ficción narrativa, el conocimiento histórico, las operaciones de la memoria. Su último libro, La memoria, la historia, el olvido (2003), establece una serie de distinciones esenciales entre las dos formas de presencia del pasado en el presente que aseguran, por un lado, el trabajo de la anamnesis, cuando el individuo "desciende a su memoria" como escribe Borges, y, por otro, la operación historiográfica. La primera diferencia es la que distingue el testimonio del documento. Si el primero es inseparable del testigo y de la credibilidad otorgada a sus palabras, el segundo permite el acceso a conocimientos que fueron recuerdos de nadie. A la estructura fiduciaria del testimonio, que supone una cierta confianza, se opone la naturaleza indiciaria del documento, sometido a los criterios objetivos de la prueba. Una segunda distinción opone la inmediatez de la memoria y la construcción explicativa de la historia, cualquiera sea la escala de análisis de los fenómenos históricos o el modelo de inteligibilidad elegido, sean las explicaciones por las causalidades desconocidas por los actores, o bien las explicaciones que privilegian sus estrategias explícitas y conscientes. De ahí una tercera diferencia, entre el reconocimiento del pasado procurado por la memoria y su representación, o "representancia", en el sentido de "tener el lugar de", asegurada por el relato histórico.

La distinción analítica entre la elección de modelos explicativos y la construcción del relato histórico permite subrayar los parentescos narrativos o retóricos entre la ficción y la historia -tal como lo mostraba un libro anterior suyo, Tiempo y narración (1995)-, sin correr el riesgo de disolver la capacidad de conocimiento de la historia en la narratividad que rige su 
escritura. Haciendo hincapié en las operaciones específicas que fundamentan tanto la intención de verdad como la práctica crítica de la historia, Ricœur rechaza todas las perspectivas que consideran que el régimen de verdad de la novela y el de la historia son idénticos. Así, retoma la afirmación de Michel de Certeau en cuanto a la capacidad de la historia de producir enunciados "científicos", si se entiende por eso "la posibilidad de establecer un conjunto de reglas que permitan 'controlar' operaciones proporcionadas para la producción de objetos determinados" (de Certeau 1993: 68). Son estas operaciones y reglas las que permiten acreditar la representación histórica del pasado y rehusar la sospecha de relativismo o escepticismo que nace del uso por la escritura historiográfica de la formas literarias: estructuras narrativas, tropos retóricos, figuras metafóricas.

El documento en contra del testimonio, la construcción explicativa en contra de la reminiscencia inmediata, la representación del pasado en contra de su reconocimiento: cada fase de la operación historiográfica se distingue así claramente del proceder de la memoria. Pero la diferencia no excluye la competencia. Por un lado, la historia intentó recientemente someter la memoria al estatus de un objeto histórico cuyos lugares de inscripción, formas de transmisión y usos ideológicos debían ser estudiados (Pomian 1999: 263-342). Por otro lado, la memoria pudo pretender una relación más verdadera, más auténtica, más comprometida, con el pasado que la historia. Fue el caso en la tradición judía, con la duradera reticencia al tratamiento historiográfico del pasado, como lo muestra Yosef Yerushalmi (2002), o fue el caso en el siglo XIX, cuando la memoria opuso un conocimiento vivo, afectivo, existencial del pasado a su neutralización distanciada e inerte por parte de los historiadores.
Ricœur sugiere que hoy en día no se trata de reivindicar la memoria en contra de la historia, sino de reconocer sus diferencias fundamentales y, también, de mostrar la relación que las une. En efecto, es en el testimonio de la memoria, en el recuerdo del testigo, que la historia encuentra la certidumbre en la existencia de un pasado que fue, que ya no es y que la operación historiográfica pretende representar adecuadamente en el presente. Como lo escribe, "la memoria sigue siendo el guardián de la última dialéctica constitutiva de la paseidad del pasado, a saber, la relación entre el 'ya no' que señala su carácter terminado, abolido, superado, y el 'sido' que designa su carácter originario $y$, en este sentido, indestructible" (Ricœur 2003: 648). Es en el entrecruzamiento entre la cientificidad de la operación historiográfica y la garantía ontológica del testimonio que Ricœur fundamenta el rechazo de las posiciones escépticas y relativistas y descarta la disolución del pasado dentro del presente (Hartog 2007).

Sin embargo, como lo sabía Cervantes para nuestro placer o para la inquietud de sus lectores, siempre la ilusión referencial se pone en relación con el pasado, cualquiera sea su registro. Es cierto, como lo muestra Roland Barthes, que las modalidades de semejante "ilusión" no son las mismas en la novela, que al abandonar la estética clásica de la verosimilitud multiplicó las notas realistas destinadas a cargar la ficción con un peso de realidad, que en la historia, para la cual "el haber-sido de las cosas es un principio suficiente del discurso" (Barthes 1984: 153174). Sin embargo, para exhibir este principio, el historiador debe introducir en su narración indicios o pruebas de este "haber-sido" que funcionan como "effets de réel", "efectos de realidad", encargados de dar presencia al pasado gracias a las citas, las fotos, los documentos. 
Para de Certeau, la construcción desdoblada de la historia se remite a tal presencia: "Se plantea como historiográfico el discurso que 'comprende' a su otro -la crónica, el archivo, el documento-, es decir el que se organiza como texto foliado en el cual una mitad, continua, se apoya sobre otra, diseminada, para poder decir lo que significa la otra sin saberlo. Por las 'citas', por las referencias, por las notas y por todo el aparato de llamadas permanentes a un primer lenguaje, el discurso se establece como saber del otro" (1993: 113). Sin embargo, el uso de semejante aparato no es siempre suficiente para proteger contra la ilusión referencial. De ahí la apropiación, por algunas ficciones, de las técnicas de la prueba propias de la historia, a fin de producir, no "efectos de realidad", sino más bien la ilusión de un discurso histórico.

Junto con las biografías imaginarias de Marcel Schwob o los textos apócrifos de Borges, como aparecen en el apéndice "Etcétera" de la Historia universal de la infamia o en la sección "Museo" de El Hacedor, se puede ubicar el Jusep Torres Campalans publicado por Max Aub en la ciudad de México en 1958 (1999). El libro pone al servicio de la biografía de un pintor imaginario todas las técnicas de la acreditación moderna del discurso histórico: las fotografías que dejan ver a los padres del artista y a éste en compañía de su amigo Picasso, las reproducciones de sus obras (expuestas en Nueva York, en 1962, con ocasión de la presentación de la traducción inglesa del libro), los recortes de la prensa donde se mencionan las entrevistas que dio Campalans en París antes de 1914, las conversaciones que Aub tuvo con él y algunos de sus contemporáneos, o el Cuaderno verde redactado por Campalans entre 1906 y 1914.
En su tiempo, la obra se burlaba de las categorías manejadas por la crítica de arte: la explicación de la obra por la biografía del artista, las nociones contradictorias y sin embargo asociadas de influencia y de precursor, las técnicas de datación y atribución de los cuadros, el desciframiento de intenciones secretas del creador. Hoy en día, esa obra tal vez puede leerse de otra manera. Al movilizar los "efectos de realidad" que comparten el saber histórico y la invención literaria, se vislumbran los parentescos que los vinculan. Pero, al multiplicar las advertencias irónicas (en particular, las numerosas referencias al Don Quijote o el epígrafe "¿Cómo puede haber verdad sin mentira?"), recuerda a sus lectores la distancia que separa a la fábula del discurso erudito, la realidad que fue y los referentes imaginarios. Junto a los libros de Caro Baroja (1992) o Anthony Grafton (2001) dedicados a las falsificaciones históricas, el Campalans de Max Aub, paradójicamente, irónicamente, reafirma la capacidad de distinguir entre el encanto o la magia de la invención de un pasado imaginado e imaginario y las operaciones críticas propias de un saber histórico capaz de desenmascarar las imposturas.

Es la razón por la cual la distinción entre historia y ficción parece clara y zanjada si se acepta con Michel de Certeau que, en todas sus formas (míticas, literarias, metafóricas), la ficción es "un discurso que se 'informa' de lo real, pero no pretende representarlo ni acreditarse en él", mientras que la historia pretende dar una representación adecuada de la realidad que fue y ya no es. En ese sentido, lo real es a la vez el objeto y el garante del discurso de la historia. Sin embargo, hoy en día muchas razones borran esa distinción tan clara. La primera, es la fuerza de las representaciones del pasado propuestas por la literatura. La noción de "energía" puede ayudar a comprender cómo algunas obras 
literarias han moldeado más poderosamente que los escritos de los historiadores de su tiempo las representaciones colectivas del pasado. Esa noción desempeña un papel esencial en la perspectiva analítica del "New Historicism". En su libro Shakespearean Negotiations, cuyo subtítulo es The Circulation of Social Energy in Renaissance England, Greenblatt (1988) define la noción de "energía social" como una noción clave, tanto para el proceso de la creación estética como para las percepciones y las experiencias de sus lectores o espectadores.

Por un lado, lo que capta la escritura literaria es la poderosa energía de los lenguajes, ritos y prácticas del mundo social. Múltiples son las formas de las negociaciones que permiten semejante captura estética del mundo social: la apropiación de los lenguajes, el uso metafórico o material (en el caso del teatro) de los objetos de lo cotidiano, la simulación de las ceremonias y discursos públicos. Por otro lado, la energía transferida en la obra literaria -lo que Greenblatt designa como "la energía social codificada en las obras literarias" o, en otra fórmula, "las formas estéticas de la energía social"- vuelve al mundo social a través de sus apropiaciones por sus lectores y espectadores. Lo que define la fuerza estética de las obras, o por lo menos de ciertas obras, es "la capacidad de algunas huellas verbales, orales y visuales de producir, plasmar y organizar experiencias colectivas tanto físicas como mentales". La circulación entre el mundo social y las obras estéticas puede apoderarse de cualquiera realidad, tanto de los deseos, las ansiedades o los sueños, como del poder, el carisma o lo sagrado: "cualquiera cosa producida por la sociedad puede circular salvo si se encuentra excluida de la circulación", por ejemplo, por la censura monárquica 0 eclesiástica (Greenblatt 1988: 6-7; 19).
A título de ejemplo, veamos las histories o piezas históricas de Shakespeare. En el folio de 1623, que reúne por primera vez, siete años después de la muerte de Shakespeare, treinta y seis de sus obras, la categoría de histories, ubicada entre las comedies y las tragedies, reúne diez obras que, siguiendo el orden cronológico de los reinados, cuenta la historia de Inglaterra desde el rey Juan hasta Enrique VIII. Esta historia representada en los escenarios de los teatros es una historia recompuesta, sometida a las exigencias de la censura (como demuestra la ausencia de la escena de la abdicación de Ricardo II en las tres primeras ediciones de la obra), y abierta a los anacronismos. Así, en su puesta en escena de la revuelta de Jack Cade y sus artesanos de Kent en 1450, como aparece en la segunda parte de Enrique VI, Shakespeare reinterpreta el hecho atribuyendo a los rebeldes de 1450 un lenguaje milenarista e igualitario, y acciones violentas, destructivas de todas las formas de la cultura escrita y de todos los que la encarnan, que los cronistas asociaban, con una menor radicalidad, por lo demás, a la revuelta de Tyler y Straw de 1381. El resultado es una representación ambivalente o contradictoria de la revuelta de 1450, que recapitula las fórmulas y los gestos de las revueltas populares, al mismo tiempo que deja ver la figura carnavalesca, grotesca y cruel de una imposible edad de oro: la de un mundo al revés, sin escritura, sin moneda, sin diferencias. La historia de las histories se basaba en la distorsión de las realidades históricas narradas por los cronistas y proponía a los espectadores una representación ambigua del pasado, habitada por la incertidumbre y la contradicción. Tal vez esto es el caso de todas las apropiaciones del pasado por la invención poética, como en la epopeyas o, más tarde, las construcciones narrativas de las novelas y películas históricas. 
$\star \star$

Hay una otra razón de la proximidad, seductora pero peligrosa, entre la historia como ejercicio de conocimiento y la ficción, sea literatura o mito. En el mundo contemporáneo, la necesidad de afirmación o de justificación de identidades construidas, o reconstruidas, y que no son todas nacionales, suele inspirar una reescritura del pasado que deforma, olvida u oculta las aportaciones del saber histórico controlado (Cf. Hobsbawm 1996). Esa deriva, impulsada por reivindicaciones con frecuencia muy legítimas, impone una reflexión epistemológica en torno a los criterios de validación aplicables a la "operación historiográfica" en sus diferentes momentos. La capacidad crítica de la historia no se limita, en efecto, a la negación de las falsificaciones o las imposturas. Puede y debe someter a criterios objetivos de validación o de rechazo las construcciones interpretativas. Si se asigna esa función a la historia, necesariamente se plantea la pregunta sobre los criterios de ese juicio: ¿Se los debe vincular a la coherencia interna de la demostración? ¿A su compatibilidad con los resultados logrados? Y, por otra parte: ¿es legítimo postular una pluralidad de regímenes de prueba de la historia que sería exigida por los diversos objetos y métodos históricos? ¿O debemos esforzarnos por elaborar una teoría de la objetividad que establezca criterios universales que permitan distinguir entre interpretaciones aceptables o inaceptables?

Estas cuestiones conllevan un reto esencial. En una época en que nuestra relación con el pasado está amenazada por la fuerte tentación de crear historias imaginadas o imaginarias, la reflexión sobre las condiciones que permiten sostener un discurso histórico como una representación y una explicación adecuadas de la realidad que fue, es fundamental y urgente. Suponiendo, en su principio, la distancia entre saber crítico y reconocimiento inmediato, esa reflexión participa del largo proceso de emancipación de la historia respecto a la memoria y a la fábula, incluso si verosímil.

La relación con el tiempo desempeña un papel esencial en este proceso. Pierre Bourdieu veía en la contemporaneidad de pasados sucesivos una de las características propias de los espacios de la producción y del consumo cultural: "Toda la historia de un campo es inmanente al funcionamiento del campo y para estar a la altura de sus exigencias objetivas, en tanto productor pero también en tanto consumidor, hay que poseer un dominio práctico o teórico de esta historia". Es dicha posesión, o su ausencia, la que distingue a doctos de ingenuos y la que gobierna las diversas relaciones que cada obra nueva entabla con el pasado: la imitación académica, la restauración kitsch, el retorno a los antiguos, la ironía satírica, la ruptura estética. Al designar como blanco de sus parodias los libros de caballería, pero también las novelas pastorales (cuando don Quijote se transforma en pastor Quijótiz) y las autobiografías picarescas (el relato de su vida redactado por el galeote Ginés de Pasamonte), Cervantes instaló en el presente de su escritura tres géneros que tenían temporalidades bien distintas y contra los cuales inventó una manera inédita de escribir la ficción, concibiéndola como ha apuntado Francisco Rico- "no en el estilo artificial de la literatura, [...] sino en la prosa familiar de la vida". Cervantes, el "ingenio lego", el genio ignorante, muestra así que los doctos no son los únicos que hacen buen uso del conocimiento de la historia de los géneros y de las formas. 
Esta modalidad de la presencia del pasado debe conducir a ubicar las obras en el cruce de dos ejes. Por una parte, un eje sincrónico, que permite situar cada producción escrita en su tiempo y ponerla en relación con otras producciones contemporáneas que pertenecen a diferentes registros de experiencia. Por otra parte, un eje diacrónico, que la inscribe en el pasado del género, de la disciplina o del campo. En las ciencias más exactas, esta presencia del pasado remite generalmente a duraciones breves, a veces muy breves. No ocurre lo mismo con la literatura o las humanidades, para las cuales los pasados recientes o más remotos están siempre, de cierta forma, presentes, incluso vivos, y de los cuales se inspiran o apartan las creaciones nuevas.

Semejante diferencia nos hace recordar que la especificidad de la historia, dentro de las ciencias humanas y sociales, concierne su capacidad de distinguir y articular los diferentes tiempos, contemporáneos, en cada momento histórico. Se debe volver aquí a la construcción temporal que sostenía todo el edificio de la historia y, más allá, de la ciencia de lo social, tal como las definía Braudel en 1958 : "La historia se ubica en niveles diferentes, diría en tres niveles, pero es una manera de decir, simplificando mucho. [...] En la superficie, la historia que se inscribe en el tiempo corto es una microhistoria. En el nivel medio, una historia coyuntural sigue un ritmo más amplio y más lento. Hasta ahora se la ha estudiado sobre todo en el plano de la vida material, los ciclos o interciclos económicos. [...] Más allá de ese "recitativo" de la coyuntura, la historia estructural, o de larga duración, cuestiona siglos enteros; está en el límite de lo móvil y lo inmóvil y, por sus valores fijos durante largo tiempo, aparece como invariante con respecto a otras historias, que pasan y se cumplen más rápido y que, en última instancia, gravitan en torno a ella" (Braudel 1997: 189190).

Me parece que podemos plantear tres cuestiones a este modelo de las duraciones superpuestas y heterogéneas. En primer lugar, ¿son tan irreductiblemente diferentes unas de otras? ¿No se ha de considerar, como hace Paul Ricœur en Tiempo y narración, que "la noción misma de la historia de larga duración deriva del acontecimiento dramático, en el sentido de acontecimiento-estructurado-entrama", del "événement mis en intrigue", y que, por ello, los tres tiempos braudelianos se remiten a una misma matriz temporal? (Ricœur 1983: 289). El tiempo largo, la "longue durée" del Mediterráneo debe comprenderse como construido según las fórmulas narrativas que articulan las temporalidades construidas de los relatos con el tiempo subjetivo del individuo. En la escritura del historiador, el tiempo del mar y el tiempo del rey se construyen según las mismas figuras.

Luego, ¿se ha de acotar el "acontecimiento" a su definición tradicional, la que lo vincula al tiempo corto, a las decisiones conscientes, a lo político? En un ensayo dedicado a Nietzsche, Michel Foucault asocia estrechamente una crítica devastadora de la noción de origen a una reformulación del concepto de acontecimiento. Para él, la brutalidad del acontecimiento debe ubicarse no en los accidentes del transcurso de la historia o las elecciones de los individuos, sino en las transformaciones de las relaciones de dominación:

Por acontecimiento ha de entenderse no una decisión, un tratado, un reino o una batalla, sino una relación de fuerzas que se invierte, un poder confiscado, un vocabulario que se retoma y se vuelve contra sus usuarios, una dominación 
que se debilita, se distiende, se envenena a sí misma y otra que hace su entrada, enmascarada. Las fuerzas que están en juego en la historia no obedecen ni a un destino ni a una mecánica, sino al azar de la lucha. No se manifiestan como las formas sucesivas de una intención primordial; tampoco adoptan la forma de un resultado necesario. Siempre estas fuerzas aparecen en las circunstancias singulares del acontecimiento (Foucault 1994: 148).

Si bien el acontecimiento, en esa lectura nietzscheana, es aleatorio, violento e inesperado, no designa la espuma de los hechos, sino las rupturas y las discontinuidades más fundamentales.

Por último, ¿se pueden considerar las temporalidades como externas a los individuos, como medidas del mundo? Pierre Bourdieu, en las Meditaciones pascalianas, subraya con insistencia que la relación con el tiempo es una de las propiedades sociales más desigualmente distribuidas: "Habría que describir, relacionándolas con sus condiciones económicas y sociales de posibilidad, las diferentes maneras de temporalizarse" (Bourdieu 1997: 265). Ser dueño de su propio tiempo, controlar el tiempo de los demás ("el todo-poderoso es el que no espera y, en cambio, hace esperar"), no tener ninguna influencia sobre el tiempo y, de golpe, dejarse llevar por los juegos de azar -totocalcio, jogo de bichoque "permiten arrancarse del tiempo anulado de una vida sin justificación y, sobre todo, sin compromiso posible" son algunas de las modalidades incorporadas de la relación con el tiempo que expresan el poder de los dominantes y la impotencia de los desfavorecidos. De modo que las diversas temporalidades no deben ser consideradas como envolturas objetivas de los hechos sociales. Son el producto de construcciones sociales que aseguran el poder de unos (sobre el presente o el futuro, sobre sí mismo o sobre los demás), y llevan a los otros a la desesperanza. Hoy la arquitectura braudeliana de las duraciones sedimentadas (larga duración, coyuntura, acontecimiento) sin duda merece repensarse.

Así, fundado sobre una reevaluación de las diferentes temporalidades que hacen que el presente es lo que es, herencia y ruptura, el conocimiento histórico debe permitir establecer lo que Paul Ricœur designa y espera como "una memoria equitativa" -equitativa porque obliga a las memorias particulares a confrontarse con una representación del pasado situada en el orden de un saber controlable y universalmente aceptable. Pero, como se sabe, si semejante distinción se encuentra teóricamente fundada, no puede y quizás no debe deshacer los lazos entre historia y memoria.

Por un lado, debemos pensar con Reinhart Koselleck que existen fuertes dependencias entre la experiencia y el conocimiento, entre las percepciones del tiempo y las modalidades de la escritura de la historia. A las tres categorías de la experiencia que son la percepción de lo irrepetible, la conciencia de la repetición y el saber de las transformaciones que escapan a la experiencia inmediata, corresponden tres maneras de escribir la historia: la historia que registra el acontecimiento único, la historia que despliega comparaciones, analogías y paralelismos, y la historia entendida como reescritura, es decir como fundada sobre los métodos y técnicas que permiten un conocimiento crítico que contribuye a "un progreso cognoscitivo acumulado" (cf. Koselleck 2001).

Por otro lado, la historia no puede ignorar las violencias que trataron o tratan de hacer desaparecer, no solo a las víctimas de las 
tiranías, sino también la posibilidad de que sean recordadas sus existencias. En este sentido, la historia nunca puede olvidar los derechos de una memoria que es una insurgencia contra la falsificación o la negación de lo que fue. La historia debe entender semejante pedido y, con su exigencia de verdad, con sus operaciones propias, identificar, exponer y, tanto cuanto sea posible, apaciguar las infinitas heridas que dejó en el presente un pasado a menudo tiránico, brutal y cruel. Pero aquí, en Chile, ustedes lo saben mejor que yo.

\section{Bibliografía}

Aub, M. 1999 [1958]. Jusep Torres Campalans. Barcelona: Destino.

Barthes, R. 1984. "L'effet de réel". Le bruissement de la langue. Essais critiques, IV. Paris: Éditions du Seuil. 153-174.

Braudel, F. 1997. "Histoire et sociologie" [1958]. Les Ambitions de l'histoire. París: Éditions de Fallois. 179-196.

Bourdieu, P. 1997. Méditations pascaliennes. Paris: Seuil.

Caro Baroja, J. 1992. Las falsificaciones de la Historia (en relación con la de España). Barcelona: Seix Barral.

de Certeau, M. 1993. La escritura de la historia. México: Universidad Iberamericana.

Foucault, M. 1994. "Nietzsche, la généalogie, la morale", en M. Foucault, Dits et écrits 1954-1988, tomo II, 1970-1975, bajo la dirección de D. Defert y F. Ewald. París: Gallimard. 136-156.

Grafton, A. 2001. Falsarios y críticos. Creatividad y duplicidad en la tradición occidental. Barcelona: Crítica.

Greenblatt, S. 1988. Shakespearean Negotiations. The Circulation of Social Energy in Renaissance England. Berkeley y Los Angeles: University of California Press.
Hartog, F. 2007. Regímenes de historicidad. Presentismo y experiencias del tiempo. Mexico: Universidad IberoAmericana.

Hobsbawn, E. 1996. "El historiador entre la búsqueda de lo universal y la búsqueda da la identidad", Historia Social 25: 81-90.

Koselleck, R. 2001. "Cambio de experiencia y cambio de método. Un apunte histórico-antopológico", en Reinhart Koselleck, Los estratos del tiempo: estudios sobre la historia. Barcelona, Buenos Aires y Mexico: Paidós. 43-92.

Pomian, K. 1999. "De l'histoire, partie de la mémoire, objet d'histoire", in Krzysztof Pomian, Sur l'histoire. Paris: Gallimard. 263-342.

Ricoeur, P. 2003. La memoria, la historia, el olvido. Madrid: Editorial Trotta. Editores. 1995. Tiempo y narración. México y Madrid: Siglo XXI 1983. Temps et récit, tomo I, L'intrigue et le récit historique. París: Éditions du Seuil.

Yerushalmi, Y. 2002. Zakhor. La historia judía y la memoria judía. Barcelona: Anthropos/ México: Fundación Cultural Eduardo Cohen. 
